\title{
Who Started, Stopped, and Continued Participating in Outdoor Recreation during the COVID-19 Pandemic in the United States? Results from a National Panel Study
}

\author{
B. Derrick Taff ${ }^{1} \mathbb{D}$, William L. Rice ${ }^{2, *}$, Ben Lawhon $^{3}$ and Peter Newman ${ }^{1}$ \\ 1 Department of Recreation, Park and Tourism Management, Pennsylvania State University, University Park, \\ State College, PA 16802, USA; bdt3@psu.edu (B.D.T.); pbn3@psu.edu (P.N.) \\ 2 Parks, Tourism, and Recreation Management Program, University of Montana, Missoula, MT 59812, USA \\ 3 The Leave No Trace Center for Outdoor Ethics, Boulder, CO 80306, USA; ben@LNT.org \\ * Correspondence: william.rice@umontana.edu; Tel.: +1-406-243-5477
}

check for

updates

Citation: Taff, B.D.; Rice, W.L.;

Lawhon, B.; Newman, P. Who Started,

Stopped, and Continued Participating

in Outdoor Recreation during the

COVID-19 Pandemic in the United

States? Results from a National Panel

Study. Land 2021, 10, 1396. https://

doi.org/10.3390/land10121396

Academic Editors: Francesca Ugolini and David Pearlmutter

Received: 4 November 2021

Accepted: 14 December 2021

Published: 17 December 2021

Publisher's Note: MDPI stays neutral with regard to jurisdictional claims in published maps and institutional affiliations.

Copyright: (c) 2021 by the authors. Licensee MDPI, Basel, Switzerland. This article is an open access article distributed under the terms and conditions of the Creative Commons Attribution (CC BY) license (https:/ / creativecommons.org/licenses/by/ $4.0 /)$.

\begin{abstract}
The COVID-19 pandemic has been proposed as a catalyst for many U.S. residents to re-engage in outdoor recreation or engage in outdoor recreation for the first time. This manuscript describes the results of a representative U.S. national panel study aimed at better understanding the socio-demographic profile (gender, ethnicity, community type, income, and age) of those participants new to outdoor recreation since the start of the COVID-19 pandemic. In doing so, we address how these new outdoor recreationists differ from (1) those who frequently participated in outdoor recreation prior to the pandemic and continue to participate in outdoor recreation, (2) those who did not frequently participate in outdoor recreation prior to the pandemic and remain un-engaged, and (3) those who frequently participated in outdoor recreation prior to the pandemic but stopped their frequent participation following the onset of the pandemic. Results from this U.S. national study suggest that $35.8 \%$ of respondents indicated that they did not participate regularly in outdoor recreation prior to the pandemic or during the pandemic, $30.4 \%$ indicated that they did participate regularly in outdoor recreation prior to the pandemic and continued to do so regularly during the pandemic, and $13.5 \%$ indicated that they did participate regularly in outdoor recreation prior to the pandemic, but did not continue to do so during the pandemic. More than $20 \%$ of the sample indicated that they were new outdoor recreationists. The majority of respondents in all categories, including those that were new to outdoor recreation amidst the pandemic, identified as being white, however these new outdoor recreationists were also the least ethnically diverse. The previously but no longer outdoor recreationist respondents were significantly more ethnically diverse than the other three groups, and they tended to live in more urbanized settings. Discussion of these results includes implications for outdoor recreation managers, and researchers who seek to better understand who the COVID-19 pandemic has influenced with regard to outdoor recreation participation. Implications regarding social justice, access and equity to public places that facilitate outdoor recreation, and health-related policies are discussed.
\end{abstract}

Keywords: COVID-19; pandemic; outdoor recreation; health; participation

\section{Introduction}

Outdoor recreation participation in the U.S. has been steadily increasing since the 1960s [1,2]. However, the COVID-19 pandemic, declared by the World Health Organization in March of 2020, has been touted as significantly accelerating this broader increase in outdoor recreation [3], although impacting different settings and demographics disproportionately $[4,5]$. This has led to concerns and challenges for public land area managers and tourism operators as they attempted to manage outdoor recreation as it fluctuated (i.e., non-existent during closures; in some settings, all-time highs during openings) as the pandemic and associated health measures evolved [6]. 
Research regarding outdoor recreation trends associated with the pandemic suggest that despite some pandemic-related closures of recreation areas, outdoor recreation use spiked significantly in some settings [7-9]. For example, in large western U.S. national parks such as Yellowstone, Grand Canyon, and Yosemite, visitation increased significantly immediately following reduced restrictions on access [10]. Another study suggested that the number of hikers in the U.S. increased by approximately 135\% from 2019 to 2020 [11]. However, the above findings reflect certain locations and demographics, as other research has noted decreases in use in locations such as urban parks, and discrepancies in visitation frequency with specific demographics [4,5]. Similarly, recreation behaviors of avid outdoor recreationists living in urban areas in the U.S. were more severely impacted by the pandemic than those residing in rural areas [12], and decisions to pursue outdoor recreation were influenced heavily by perceptions of risk $[13,14]$. Motivations for pursuing outdoor recreation during this period have been largely driven by needs associated with personal health and well-being [15], such as relieving stress and supporting mental health, and facilitating physical health through outdoor exercise [16]. And, research in the U.S. indicates that outdoor recreation during the pandemic has in fact, led to improved mental health outcomes $[17,18]$. Similar health-related trends have been discovered internationally $[5,19,20]$.

Despite the limited but growing body of research regarding outdoor recreation as it relates to the pandemic, very little is known about U.S. outdoor recreation participants during this time. For example, are there new outdoor recreationists, driven to participation by the pandemic? The Outdoor Industry Association and Naxion Research Consulting [21] began exploring this question through a national panel of $n=613$ participants that had either "engaged in outdoor activities for the first time or for the first time in more than a year since the onset of the COVID-19 pandemic" or "participated in outdoor activities before the pandemic" (p. 21). This study indicated that outdoor recreationists during the pandemic tend to consist of more females, are generally younger, more likely to live in urban areas, and represent a slightly lower socioeconomic bracket than pre-pandemic outdoor recreation participants [21]. While these findings represent an important initial step in improving understanding of outdoor recreationists during the pandemic, the criteria for being considered as a new or existing outdoor recreation participant was as little as one occurrence [21]. Furthermore, the study was purposefully weighted to match the U.S. population for gender, ethnicity, age, household income, and region [21]. This robust census-matching approach is common for U.S. panel studies, but by purposefully defining the demographic criteria, it may inaccurately represent actual new or existing outdoor recreation participants. Additionally, the criteria for being considered as a "new outdoor participant" was fairly minimal (i.e., as little as one occurrence) and not mutually exclusive (i.e., first time in more than a year since the onset of the COVID-19 pandemic" or "participated in outdoor activities before the pandemic") [21]. Finally, other pandemic and recreation-related research has highlighted inequities and decreases in recreational opportunities for some demographics amidst the pandemic [4,5,12], further driving the need for more understanding regarding recreation behaviors and demographics during this unique period of time.

The purpose of this study was to further advance this initial research by examining U.S. outdoor recreation demographic trends amidst the pandemic, by applying slightly different methodological approaches than those used by the Outdoor Industry Association and Naxion Research Consulting [21]. Additionally, given that there are currently no national studies examining the demographics of new, current, and non-outdoor recreationist during this unique and challenging time (at the time of this publication nearly two years since the World Health Organization's pandemic declaration), this study advances understanding of these trends as well. Specifically, the purpose of this study is to examine how new outdoor recreationists differ from those who frequently participated in outdoor recreation prior to the pandemic and continue to participate in outdoor recreation, those who did not frequently participate in outdoor recreation prior to the pandemic and remain un-engaged, 
and finally, those who frequently participated in outdoor recreation prior to the pandemic but stopped their frequent participation following the onset of the pandemic.

\section{Materials and Methods}

This study used panel data, collected through Qualtrics International Inc. following Institutional Review Board approval through the lead author's University. Data were collected through a paid panel of participants purposefully targeting adults age 18 or older, residing within one of four geographically representative regions of the U.S., including the Northeast, South, Midwest, and West [22]. While one main purpose was to further define new outdoor recreation participants amidst the pandemic, we first screened participants to determine who is, who is not, and who was but is no longer an outdoor recreationist. Our goal was to collect a geographically representative sample of $n=1000$ new outdoor recreationists in the U.S. This sample estimate was informed by empirical political science studies regarding sample size and inference, and recent nationwide COVID-19 vaccination compliance research using similar sample sizes e.g., [23,24].

These data were not purposefully controlled to match the U.S. census, but rather were allowed to be collected in a manner that represents the U.S. geographically, based on outdoor recreation participation prior to and during the pandemic. This allowed us to determine who these individuals are, rather than place census parameters in which demographics may not match these outdoor recreationists groups. Panel respondents were screened by inquiring whether or not they were "new or returning to frequent outdoor recreation since the COVID-19 pandemic began" (Table 1). This was defined for respondents as "someone who has started pursuing activities undertaken for recreation in nature-based environments that generally involve some level of intentional physical exertion, at least ONCE PER MONTH since March 2020, when the COVID-19 pandemic began."

Table 1. Example of screening questions and subsequent groupings.

\begin{tabular}{ccccc}
\hline & Participant Group & & \\
\hline & $\begin{array}{c}\text { Non-Outdoor } \\
\text { Recreationist }\end{array}$ & $\begin{array}{c}\text { Existing Outdoor } \\
\text { Recreationist }\end{array}$ & $\begin{array}{c}\text { Previous, but No } \\
\text { Longer Outdoor } \\
\text { Recreationist }\end{array}$ & $\begin{array}{c}\text { New Outdoor } \\
\text { Recreationist }\end{array}$ \\
\hline $\begin{array}{c}\text { Participated in } \\
\text { outdoor recreation } \\
\text { regularly prior to } \\
\text { pandemic? }\end{array}$ & No & Yes & Yes & No \\
\hline $\begin{array}{c}\text { Participated in } \\
\text { outdoor recreation } \\
\text { regularly during } \\
\text { pandemic? }\end{array}$ & No & Yes & No & Yes \\
\hline
\end{tabular}

The definition of outdoor recreation was derived from the U.S. Bureau of Economic Analysis's definition: "All recreational activities undertaken for pleasure that generally involve some level of intentional physical exertion and occur in nature-based environments outdoors" [25] (p. 4). This more stringent definition and criteria for evaluating outdoor recreation participation was purposefully chosen to provide information for land managers and the outdoor recreation industry regarding consistent and fairly frequent outdoor recreationists. Outdoor recreation activities such as hiking, running outdoors, fishing, gardening, camping or RVing, boating or sailing, and surfing for example, listed in the survey instrument, mimicked previous research on national outdoor recreation participation [21]. Respondents were categorized into the four groups listed in Table 1 and responses in all categories propagated until the quota of $n=1000$ new outdoor recreationists in the U.S. was met. Thus, data collection began on the 10th of May 2021, and concluded on the 13th of June 2021, allowing for more than one-year of pandemic conditions to be considered as context for the respondents.

Qualtrics conducted ongoing data cleaning throughout this period to ensure the sample was collecting valid responses. Two binary questions asking about the same behaviors were placed at different points in the survey to ensure identical responses. 
When identical responses were not recorded, the survey was removed from the dataset. Further cleaning measures ensured that respondents were not "straight-lining" (answering the same response to each question) [26]. Statistical comparisons between the four groups were analyzed using analyses of variance and Kruskal-Wallis $\mathrm{H}$ tests through social science statistics software (SPSS) - depending on the nature of the variables measured (nominal vs. continuous).

\section{Results}

\subsection{Non, Existing, Previous but No Longer, and New Outdoor Recreationists Groups}

Based on the initial screening questions, $n=1763 ; 35.8 \%$ of respondents indicated that they did not participate regularly in outdoor recreation prior to the pandemic or during the pandemic (Table 2). These individuals are noted as "non-outdoor recreationists." A total $n=1501 ; 30.4 \%$ indicated that they did participate regularly in outdoor recreation prior to the pandemic, and continued to do so regularly during the pandemic. These individuals are noted as "existing outdoor recreationists." The smallest subset of respondents $(n=665 ; 13.5 \%)$ indicated that they did participate regularly in outdoor recreation prior to the pandemic, but did not continue to do so during the pandemic. We note these respondents as "previous, but no longer outdoor recreationists". Finally, the sample quota of $n=1000(20.3 \%$ of the overall sample) "new outdoor recreationists" were collected for comparison.

Table 2. Breakdown of non, existing, no longer, and new outdoor recreationists.

\begin{tabular}{|c|c|c|c|c|}
\hline \multicolumn{5}{|c|}{ Participant Group } \\
\hline & $\begin{array}{l}\text { Non-Outdoor } \\
\text { Recreationist }\end{array}$ & $\begin{array}{l}\text { Existing Outdoor } \\
\text { Recreationist }\end{array}$ & $\begin{array}{c}\text { Previous, but No } \\
\text { Longer Outdoor } \\
\text { Recreationist }\end{array}$ & $\begin{array}{l}\text { New Outdoor } \\
\text { Recreationist }\end{array}$ \\
\hline $\begin{array}{l}\text { Participated in } \\
\text { outdoor recreation } \\
\text { regularly prior to } \\
\text { pandemic? }\end{array}$ & No & Yes & Yes & No \\
\hline \multirow[t]{2}{*}{$\begin{array}{l}\text { Participated in } \\
\text { outdoor recreation } \\
\text { regularly during } \\
\text { pandemic? }\end{array}$} & No & Yes & No & Yes \\
\hline & $(n=1763)$ & $(n=1501)$ & $(n=665)$ & $(n=1000)^{\mathrm{a}}$ \\
\hline Percent of total & $35.8 \%$ & $30.4 \%$ & $13.5 \%$ & $20.3 \%$ \\
\hline
\end{tabular}

a Sampling ceased once 1000 valid responses were collected for the No $\rightarrow$ Yes group.

\subsection{Demographics and Respondent Categories}

Demographic comparisons were examined to determine statistical differences between the groups based on gender, ethnicity, community type, income, and age (Table 3). There were significantly more respondents identifying as women in the non-outdoor recreationist group compared to the other categories (existing, those that stopped, and those that are new). While the overall sample had more female respondents than male, there were not statistically significant differences in gender between the existing, previous but no longer, and new outdoor recreationists groups.

With regard to ethnicity, the majority of respondents in all four categories identified as being white. Within the non, existing, and new outdoor recreationist groups, the percentage of white respondents ranged between $73.4 \%$ to $76.6 \%$. Ethnicity was not statistically different between these groups, and the least ethnically diverse group resulted from the new outdoor recreationists category. The previously but no longer outdoor recreationists respondents were significantly different that the other three categories, as they were more ethnically diverse compared to the other groups. 
Table 3. Breakdown of non, existing, no longer, and new outdoor recreationists by demographics.

\begin{tabular}{|c|c|c|c|c|}
\hline \multicolumn{5}{|c|}{ Participant Group } \\
\hline & $\begin{array}{l}\text { Non-Outdoor Recreationist } \\
\qquad(n=1763) ; 35.8 \%\end{array}$ & $\begin{array}{c}\text { Existing Outdoor } \\
\text { Recreationist } \\
(n=1501) ; 30.4 \%\end{array}$ & $\begin{array}{c}\text { Previous, but No Longer } \\
\text { Outdoor Recreationist } \\
(n=665) ; 13.5 \%\end{array}$ & $\begin{array}{l}\text { New Outdoor Recreationist } \\
\qquad(n=1000) ; 20.3 \%\end{array}$ \\
\hline \multicolumn{5}{|c|}{ Gender $^{1}$} \\
\hline Woman & $71.0 \%(1252)$ & $61.9 \%(929)$ & $62.1 \%(413)$ & $61.7 \%(617)$ \\
\hline Man & $27.2 \%(479)$ & $36.0 \%(541)$ & $35.5 \%(236)$ & $36.2 \%(362)$ \\
\hline Non-binary & $0.9 \%(15)$ & $1.5 \%(23)$ & $1.4 \%(9)$ & $1.7 \%(17)$ \\
\hline Prefer not to disclose & $0.6 \%(11)$ & $0.5 \%(7)$ & $0.9 \%(6)$ & $0.2 \%(2)$ \\
\hline Prefer to self-describe & $0.3 \%(6)$ & $0.1 \%(1)$ & $0.2 \%(1)$ & $0.2 \%(2)$ \\
\hline Differences between groups ${ }^{6}$ & A & B & B & B \\
\hline \multicolumn{5}{|c|}{ Ethnicity ${ }^{2}$} \\
\hline White & $74.8 \%(1318)$ & $73.4 \%(1101)$ & $61.8 \%(411)$ & $76.6 \%(766)$ \\
\hline $\begin{array}{c}\text { Hispanic or } \\
\text { Latina/Latino/Latinx }\end{array}$ & $7.1 \%(126)$ & $7.4 \%(111)$ & $11.9 \%(79)$ & $7.5 \%(75)$ \\
\hline Black or African American & $9.2 \%(163)$ & $11.3 \%(170)$ & $14.7 \%(98)$ & $8.0 \%(80)$ \\
\hline $\begin{array}{l}\text { Native American, American } \\
\text { Indian, or Alaska Native }\end{array}$ & $1.2 \%(21)$ & $1.2 \%(18)$ & $2.0 \%(13)$ & $1.0 \%(10)$ \\
\hline Asian or Pacific Islander & $5.0 \%(88)$ & $4.6 \%(69)$ & $6.3 \%(42)$ & $5.5 \%(55)$ \\
\hline Other & $1.4 \%(24)$ & $1.3 \%(19)$ & $1.7 \%(11)$ & $1.1 \%(11)$ \\
\hline Prefer not to say & $1.3 \%(23)$ & $0.9 \%(13)$ & $1.7 \%(11)$ & $0.3 \%(3)$ \\
\hline Differences between groups ${ }^{6}$ & A & A & B & $\mathrm{A}$ \\
\hline \multicolumn{5}{|c|}{ Community Type ${ }^{3, *}$} \\
\hline Rural (population < 5000) & $30.9 \%(545)$ & $31.2 \%(469)$ & $25.9 \%(172)$ & $29.7 \%(297)$ \\
\hline $\begin{array}{l}\text { Urban cluster (population } \\
\text { between } 5000 \text { and } 50,000 \text { ) }\end{array}$ & $25.0 \%(440)$ & $26.6 \%(400)$ & $22.4 \%(149)$ & $24.6 \%(246)$ \\
\hline $\begin{array}{c}\text { Urbanized area } \\
\text { (population }>50,000)\end{array}$ & $44.1 \%(778)$ & $42.1 \%(632)$ & $51.7 \%(334)$ & $45.7 \%(457)$ \\
\hline Differences between groups ${ }^{6}$ & A & A & B & A \\
\hline \multicolumn{5}{|c|}{ Income $^{4}$} \\
\hline$\$ 0-\$ 40,000$ & $53.8 \%(948)$ & $40.7 \%(611)$ & $47.2 \%(314)$ & $39.3 \%(393)$ \\
\hline$\$ 41,000-\$ 60,000$ & $17.8 \%(314)$ & $22.6 \%(339)$ & $20.2 \%(134)$ & $21.1 \%(221)$ \\
\hline$\$ 61,000-\$ 80,000$ & $10.6 \%(187)$ & $14.5 \%(217)$ & $13.1 \%(87)$ & $14.5 \%(145)$ \\
\hline$>\$ 80,000$ & $17.8 \%(314)$ & $22.3 \%(334)$ & $19.5 \%(130)$ & $25.1 \%(251)$ \\
\hline Differences between groups ${ }^{6}$ & A & B & $\mathrm{C}$ & B \\
\hline \multicolumn{5}{|c|}{ Age $^{5}$} \\
\hline Mean & 54 & 46 & 44 & 42 \\
\hline Differences between groups ${ }^{7}$ & A & B & $\mathrm{B}, \mathrm{C}$ & $\mathrm{C}$ \\
\hline
\end{tabular}

${ }^{1}$ A Kruskal-Wallis $\mathrm{H}$ test showed that a statistically significant difference exists in gender between the participant groups at a $99.9 \%$ confidence interval. ${ }^{2}$ A Kruskal-Wallis $\mathrm{H}$ test showed that a statistically significant difference exists in ethnicity between the participant groups at a $99.9 \%$ confidence interval. ${ }^{3} \mathrm{~A}$ Kruskal-Wallis $\mathrm{H}$ test showed that a statistically significant difference exists in community types between the participant groups at a $99.9 \%$ confidence interval. ${ }^{4}$ A Kruskal-Wallis $\mathrm{H}$ test showed that a statistically significant difference exists in income between the participant groups at a $99.9 \%$ confidence interval. ${ }^{5}$ Welch's ANOVA test showed a statistically significant difference exists in age between the participant groups at a $99.9 \%$ confidence interval. ${ }^{6}$ Different letters indicate significantly different $(p<0.05)$ group compositions using a Dunn's post-hoc test. ${ }^{7}$ Different letters indicate significantly different $(p<0.05)$ means using a Tamhane's T2 post-hoc test. * New outdoor recreationists indicated residing in the following geographic areas of the U.S.: Northeast $n=210$; South $n=190$; Midwest $n=370$; West $n=230$. Note: Tests used to analyze differences between participant groups were determined based on guidance from $[26,27]$.

The results of residential community type mimicked the ethnicity findings. More than half of the previous but no longer outdoor recreationists group indicated residing in urbanized areas with a population of more than 50,000. The previous but no longer recreationists group also represented the smallest percentage of individuals living in rural communities under 5000. The non, existing, and new did not differ significantly by residential area type, but the largest proportions for these three groups lived in urbanized areas, ranging from approximately $42.1 \%$ to $45.7 \%$.

With regard to income only the new and existing outdoor recreationists were similar. These two groups differed significantly (i.e., generally larger annual income) from the non and previous but no longer outdoor recreationists, and the non and previous but no longer resulted in statistically significant differences as well. The new outdoor recreationists had the largest percentage of individuals reporting annual incomes of greater than $\$ 80,000(25.1 \%)$ as well as the smallest percentage of individuals making $\$ 0-\$ 40,000$ annually. The majority of non outdoor recreationists indicated earing $\$ 0-\$ 40,000$ annually $(53.8 \%)$, which was the 
largest percentage of respondents compared to the other groups, followed by previous but no longer $(47.2 \%)$.

The new outdoor recreationists were significantly younger than non outdoor recreationists, as this category, on average was the youngest group $(M=42)$. The non outdoor recreationists were also significantly older $(M=54)$ than the other groups (existing $M=46$; previous but no longer $M=44$ ).

\section{Discussion}

This is one of the first studies to examine new outdoor recreationists during this unique and challenging time in history, while also exploring who is, who is not, and who was but is no longer an outdoor recreationist. These results highlight the substantive amount of U.S. residents that now consider themselves as outdoor recreationists. Based on this geographically-representative sample, this could be as much as half of the U.S. population.

It is concerning from the public health standpoint that $13.5 \%$ of respondents stopped outdoor recreation during the pandemic. This points to inequities associated with access to public lands as health resources [28], based on demographic differences. For example, previous but no longer respondents were significantly more ethnically diverse, and tended to reside in more urban environments and earn less annually than the other groups. This aligns with recent findings from an exploration of park use in New York City during the pandemic, where the gap between a sense of belonging in greenspace grew across racial and economic lines [29], and aforementioned research as well [4,5]. This is alarming for land managers, land use planners, and policy makers, and points to the need for continuing efforts that increase equity and access with regard to outdoor recreation opportunities and public park and protected areas.

On the other hand, it is also encouraging from the public health perspective that amidst one of the more challenging periods in recent history, that a new group of U.S. outdoor recreationists $(20 \%)$ have emerged during the pandemic, likely benefiting from the health outcomes they receive from these activities $[16-20,28]$. This creates a tremendous opportunity to engage this group of new recreationists in life-long healthy recreation and conservation behaviors that promote the preservation of the resources, sustaining outdoor recreation.

However, it must be highlighted again, that with regard to equity, these new outdoor recreationists tend to be predominantly white, and in general are less diverse, and have higher annual incomes than the other groups analyzed in this study. Furthermore, the new outdoor recreationists are largely not very different demographically, from existing outdoor recreationists. They are predominantly white, on average in their early $40 \mathrm{~s}$, with perhaps more disposable income. These two groups do however, differ from non-outdoor recreationists in the U.S. For example, on average new outdoor recreationists are twelve years younger than non-outdoor recreationists, on average. Finally, there were significantly more women, proportionately, in the non-outdoor recreationists group, pointing to the large body of empirical research that has highlighted gender inequities and associated constraints with regard to outdoor recreation participation e.g., [30,31].

While this study purposefully did not recruit or weight data based on the U.S. census (beyond region), these results in some circumstances align with other new outdoor recreation studies e.g., [21] suggesting that these individuals are slightly younger, and living in more urban environments. However, our results did not align with previous research [21] with regard to ethnicity or income, as the new outdoor recreationists in this study are predominantly white with higher reported annual incomes. These results also align with other national research regarding outdoor recreation trends [32], not associated with the pandemic, suggesting that approximately half of the U.S. population now participates in outdoor recreation. However, the national outdoor recreation participation frequency criteria established in this study (i.e., once per month) is more stringent than previous national studies, suggesting a substantial increase in participation since the pandemic began. 
There were several notable limitations to this research, which should be addressed by future studies. We used a paid Qualtrics panel, which may have influenced responses and representativeness. The classification of outdoor recreation activities [21,25] may have missed some important behaviors, particularly more passive activities such as simply relaxing outdoors. Future research should consider broadening outdoor recreation activities to include both active and passive behaviors. This study purposefully did not weight the sample to match the U.S. census, which could be done with future samples for comparison. Data collection took place in May and June of 2021, over a year into the pandemic, which could have influenced responses in a variety of ways. It would be informative if future research could ask the same questions of these respondents at multiple points over the next few years. The grouped samples as a whole tended to consist of more female respondents. While national trends indicate that an increasing proportion of women are participating in outdoor recreation, our overarching results are perhaps skewed slightly based on the gender distribution we received from our sampling approach.

This study used Qualtrics to facilitate the paid panel, but comparing these results with other paid panel services (e.g., MTurk) would be useful methodologically. While the new outdoor recreationists may not differ substantially from existing with regard to demographics, it is unknown how their behaviors might differ. Additional analyses examining how these new outdoor recreationists behave (i.e., activities, locations, frequency, anticipated future behaviors) are needed to further inform long-term public land management and associated policies. We did not ask previous but no longer outdoor recreationists why they no longer participate, and future research must address why the previous but no longer outdoor recreationists are not able to pursue these activities any longer. Is it access, fiscal constraints, fear of virus transmission, or other reasons that have led to a halt in these activities? Finally, it is important to recognize that annual income and leisure time may have been abnormal for respondents during this unique period in time, and may have influenced results. Future research exploring outdoor recreation behaviors should consider asking about specific fluctuations in income and spare time as it pertains to the pandemic.

\section{Conclusions}

This study examined who is new to outdoor recreation amidst the COVID-19 pandemic. This research also explored who is not, those who were but are no longer, and finally, those who have been and still remain an outdoor recreationist in the U.S. To our knowledge, this is one of the first national studies to examine these important groups and differences between them demographically. This research suggests that amidst the pandemic, approximately half of the U.S. population now participates in outdoor recreation, at least once per month (at the time of this study/manuscript).

Several important demographic differences exist between the groups discovered through this study, as new recreationists tend to be younger and wealthier than the other three groups. Non outdoor recreationists are older, earn less annually, and tend to consists of more females than the other groups. Non, existing, and new outdoor recreationists are predominantly white. Previous but no longer outdoor recreationists are the most ethnically diverse, and this group tends to live in more urban environments and make less annually than the other groups. Demographically, new outdoor recreationists are not vastly different from existing outdoor recreationists.

This study highlights demographic inequity issues with regard to outdoor recreation pursuits, particularly during the pandemic, meriting greater focus on this important social justice issue. Access to outdoor recreation, the parks and protected areas that facilitate recreational health benefits remains a concern in the U.S. Future research must expand upon why these inequities continue to exist and inform strategies and policies that promote equal opportunities and access to outdoor recreation, for all.

Policy makers must work harder to ensure that access and availability to outdoor recreation is equitable. Finally, land managers and public health officials may consider employing additional and new ways to encourage diverse demographics to enjoy outdoor 
recreation. A vital strategy that merits more attention is the promotion of outdoor recreation activities and the places they occur, as health resources [28].

Author Contributions: Conceptualization, P.N., B.L., W.L.R. and B.D.T.; methodology, W.L.R., P.N., B.L. and B.D.T.; formal analysis, W.L.R.; original draft preparation, B.D.T.; writing-review and editing, P.N., B.L. and W.L.R. All authors have read and agreed to the published version of the manuscript.

Funding: This research was funded through the Recreation, Park and Tourism Management Department at Pennsylvania State University and the Leave No Trace Center for Outdoor Ethics.

Institutional Review Board Statement: The study was conducted according to the guidelines of the Declaration of Helsinki, and approved by the Institutional Review Board (or Ethics Committee) of Pennsylvania State University (STUDY00017511; date of approval 4-23-2021).

Informed Consent Statement: Informed consent was obtained from all subjects involved in the study.

Conflicts of Interest: The authors declare no conflict of interest.

\section{References}

1. Clawson, M. Outdoor recreation: Twenty-five years of history, twenty-five years of projection. Leis. Sci. 1985, 7, 73-99. [CrossRef]

2. Cordell, H.K.; McDonald, B.L.; Teasley, R.J.; Bergstrom, J.C.; Martin, J.; Bason, J.; Leeworthy, V.R. Outdoor recreation participation trends. In Outdoor Recreation in American Life: A National Assessment of Demand and Supply Trends; Cordell, H.K., Betz, C., Bowker, J.M., English, D.B.K., Mou, S.H., Bergstrom, J.C., Teasley, R.J., Tarrant, M.A., Loomis, J., Eds.; Sagamore Publishing: Champaign, IL, USA, 1999; pp. 219-321.

3. Chronback, U. National parks are logging record crowds. Here's how to visit safely. Pop. Sci. 2020. Available online: https:/ / www.popsci.com/story/environment/national-parks-record-crowds-covid-pandemic/ (accessed on 15 October 2020).

4. Larson, L.R.; Zhang, Z.; Oh, J.I.; Beam, W.; Ogletree, S.S.; Bocarro, J.N.; Lee, K.J.; Casper, J.; Stevenson, K.T.; Hipp, J.A.; et al. Urban park use during the COVID-19 pandemic: Are socially vulnerable communities disproportionately impacted? Front. Sustain. Cities 2021, 3, 710243. [CrossRef]

5. Astell-Burt, T.; Feng, X. Time for 'Green' during COVID-19? Inequities in Green and Blue Space Access, Visitation and Felt Benefits. Int. J. Environ. Res. Public Health 2021, 18, 2757. [CrossRef]

6. Spenceley, A.; McCool, S.; Newsome, D.; Baez, A.; Barborak, J.R.; Blye, C.-J.; Bricker, K.; Cahyadi, H.S.; Corrigan, K.; Halpenny, E.; et al. Tourism in protected and conserved areas amid the COVID-19 pandemic. Parks 2021, 27, 103-118. Available online: https: / / researchrepository.murdoch.edu.au/id/eprint/60318/1/conserved\%20areas.pdf (accessed on 4 August 2021). [CrossRef]

7. Oftedal, A.O. Trail Use Has Surged in Response to the COVID-19 Pandemic; Parks \& Trails Council of Minnesota: St. Paul, MN, USA, 2020; Available online: https:/ / www.parksandtrails.org/2020/04/27/trail-use-covid19/ (accessed on 4 August 2021).

8. Fernandez, P.; Bron, G.; Kache, P.; Tsao, J.; Bartholomay, L.; Hayden, M.; Ernst, K.; Berry, K.; Diuk-Wasser, M. Shifts in outdoor activity patterns in the time of COVID-19 and its implications for exposure to vector-borne diseases in the United States. Res. Sq. 2021. [CrossRef]

9. Venter, Z.; Barton, D.; Gunderson, V.; Figari, H.; Nowell, M. Urban nature in a time of crisis: Recreational use of green space increases during the COVID-19 outbreak in Oslo. Natl. Environ. Res. Lett. 2020, 15, 104075. [CrossRef]

10. Kupfer, J.A.; Li, Z.; Ning, H.; Huang, X. Using mobile device data to track the effects of the COVID-19 Pandemic on spatiotemporal patterns of national park visitation. Sustainability 2021, 13, 9366. [CrossRef]

11. Ronto, P. Hiking in the U.S. Has Never Been More Popular. Run Repeat. 2021. Available online: https://runrepeat.com/hikingnever-more-popular (accessed on 1 November 2021).

12. Rice, W.L.; Mateer, T.J.; Reigner, N.; Newman, P.; Lawhon, B.; Taff, B.D. Changes in recreational behaviors of outdoor enthusiasts during the COVID-19 pandemic: Analysis across urban and rural communities. J. Urban Ecol. 2020, 6, juaa020. [CrossRef]

13. Landry, C.E.; Bergstrom, J.; Salazar, J.; Turner, D. How has the COVID-19 pandemic affected outdoor recreation in the U.S.? A revealed preference approach. Appl. Econ. Perspect. Policy 2020, 43, 443-457. [CrossRef]

14. Rice, W.L.; Mateer, T.J.; Newman, P.; Lawhon, B.; Reigner, N.; Taff, B.D. Outdoor recreationists' perceptions of risk, agency trust, and visitor capacities during the COVID-19 pandemic. J. Park Recreat. Adm. 2021. [CrossRef]

15. Harris, B.; Rigolon, A.; Fernandez, M. Hiking during the COVID-19 pandemic: Demographic and visitor group factors associated with public health compliance. J. Leis. Res. 2021, 1-9. [CrossRef]

16. Mateer, T.J.; Rice, W.L.; Taff, B.D.; Lawhon, B.; Reigner, N.; Newman, P. Psychosocial factors influencing outdoor recreation during the COVID-19 pandemic. Front. Sustain. Cities 2021, 3, 621029. [CrossRef]

17. Jackson, B.S.; Stevenson, K.T.; Larson, L.R.; Peterson, N.M.; Seekamp, E. Outdoor activity participation improves adolescents' mental health and well-being during the COVID-19 pandemic. Int. J. Environ. Res. Public Health 2021, 18, 2506. [CrossRef] [PubMed] 
18. Larson, L.R.; Mullenbach, L.E.; Browning, M.H.; Rigolon, A.; Thomsen, W.J.; Covelli, M.W.E.; Labib, S.M. Greenspace and park use associated with less emotional distress among college students in the United States during the COVID-19 pandemic. Environ. Res. 2021, 204, 112367. [CrossRef]

19. Labib, S.M.; Browning, M.H.E.M.; Rigolon, A.; Helbich, M.; James, P. Nature's Contributions in Coping with a Pandemic in the 21st Century: A Narrative Review of Evidence during COVID-19. EcoEvo 2021. Available online: https:/ / ecoevorxiv.org/j2pa8/ (accessed on 1 November 2021).

20. Ribeiro, A.I.; Triguero-Mas, M.; Santos, C.J.; Gomez-Nieto, A.; Cole, H.; Anguelovski, I.; Silva, F.M.; Baro, F. Exposure to nature and mental health outcomes during COVID-19 lockdown. A comparison between Portugal and Spain. Environ. Int. 2021, 154, 106664. Available online: https:/ / pubmed.ncbi.nlm.nih.gov/34082237/ (accessed on 1 August 2021). [CrossRef]

21. Outdoor Industry Association; Naxion Research Consulting. 2021 Special Report: The New Outdoor Participant (COVID and Beyond). Outdoor Industry Association. 2021. Available online: https:/ / outdoorindustry.org/resource/2021-special-report-newoutdoor-participant-covid-beyond/ (accessed on 1 August 2021).

22. Qualtrics ESOMAR's 28 Questions to Help Buyers of Online Samples. 2012. Available online: https:/ /www.esomar.org/uploads / public/knowledge-and-standards/documents / ESOMAR-28-Questions-to-Help-Buyers-of-Online-Samples-September-2012 .pdf (accessed on 1 August 2021).

23. Mullinix, K.J.; Leeper, T.J.; Druckman, J.N.; Freese, J. The generalizability of survey experiments. J. Exp. Political Sci. 2015, 2, 109-138. [CrossRef]

24. Khubchandani, J.; Sharma, S.; Price, J.H.; Wiblishauser, M.J.; Sharma, M.; Webb, F.J. COVID-19 vaccination hesitancy in the United States: A rapid national assessment. J. Community Health 2021, 46, 270-277. [CrossRef]

25. Highfill, T.; Franks, C.; Georgi, P.S.; Howells, T.F. Introducing the outdoor recreation satellite account. Surv. Curr. Bus. 2018, 98, 1-9. Available online: https://apps.bea.gov/scb/2018/03-march/0318-protytype-statistics-for-the-outdoor-recreation-satelliteaccount.htm (accessed on 1 August 2021).

26. Vaske, J. Survey Research and Analysis: Applications in Parks, Recreation and Human Dimensions; Venture Publishing: State College, PA, USA, 2008.

27. Calver, M.; Fletcher, D. When ANOVA isn't ideal: Analyzing ordinal data from practical work in biology. Am. Biol. Teach. 2020, 82, 289-294. [CrossRef]

28. Razani, N. Nature and health in practice. Park Steward. Forum 2021, 37, 17-22. Available online: https:/ / escholarship.org/uc/ item/1rq7m979 (accessed on 1 November 2021). [CrossRef]

29. Pipitone, J.M.; Jovic, S. Urban green equity and COVID-19: Effects on park use and sense of belonging in New York City. Urban For. Urban Green. 2021, 65, 127338. [CrossRef]

30. Lee, J.-H.; Scott, D.; Floyd, M.F. Structural inequalities in outdoor recreation participation: A multiple hierarchy stratification perspective. J. Leis. Res. 2001, 3, 4. [CrossRef]

31. Johnson, C.Y.; Bowker, J.M.; Cordell, K.H. Outdoor recreation constraints: An examination of race, gender, and rural dwelling. J. Rural. Soc. Sci. 2001, 17, 6. Available online: https://egrove.olemiss.edu/jrss/vol17/iss1/6/ (accessed on 1 August 2021).

32. Outdoor Industry Association, 2021 Outdoor Participation Trends Report. 2021. Available online: https://ip0o6y1ji424m064 1msgjlfy-wpengine.netdna-ssl.com/wp-content/uploads/2015/03/2021-Outdoor-Participation-Trends-Report.pdf (accessed on 1 November 2021). 